\title{
BOnitoring of the sciatic nerve during hamstring lengthening by evoked EMG
}
K. Katz,
J. Attias,
D. Weigl,
A. Cizger,
E. Bar-on

From Tel Aviv and

Haifa Universities,

Tel Aviv and Haifa,

Israel
K. Katz, MD, Associate Professor, Orthopaedic Surgeon

D. Weigl, MD, Orthopaedic Surgeon

E. Bar-on, MD, Lecturer

Orthopaedic Surgeon

A. Cizger, MD

Orthopaedic Unit and

Institutes of Clinical

Neurophysiology and

Audiology, Schneider

Children's Medical Centre of

Israel, Petah Tiqva, Sackler

Faculty of Medicine, Tel Aviv

University, Tel Aviv, Israel.

J. Attias, DSc, Professor

Department of

Communication, Haifa

University, Mount Carmel,

Haifa 31905, Israel.

Correspondence should be sent to Professor K. Katz.

C2004 British Editorial

Society of Bone and

Joint Surgery

doi:10.1302/0301-620X.86B7.

$14358 \$ 2.00$

$J$ Bone Joint Surg [Br]

2004;86-B:1059-61.

Received 26 March 2003;

Accepted after revision

1 October 2003

Traction injury to the sciatic nerve can occur during hamstring lengthening. The aim of this study was to monitor the influence of hamstring lengthening on conduction in the sciatic nerve using evoked electromyography (EMG).

Ten children with spastic cerebral palsy underwent bilateral distal hamstring lengthening. Before lengthening, the evoked potential was recorded with the patient prone. During lengthening, it was recorded with the knee flexed to $90^{\circ}, 60^{\circ}$ and $30^{\circ}$, and at the end of lengthening with the hip and knee extended.

In all patients, the amplitude of the evoked EMG gradually decreased with increasing lengthening. The mean decrease with the knee flexed to $60^{\circ}$ was $34 \%$ (10 to 77), and to $30^{\circ}$, $86 \%$ (52 to 98) compared with the pre-lengthening amplitude. On hip extension at the end of the lengthening procedure, the EMG returned to the pre-lengthening level.

Monitoring of the evoked EMG potential of the sciatic nerve during and after hamstring lengthening, may be helpful in preventing traction injury.

Shortening of the hamstring muscles can cause flexion contracture of the knee, crouch gait, high energy expenditure, and poor sitting posture in children with spastic cerebral palsy. Treatment by surgical elongation of the hamstrings may be indicated. ${ }^{1}$ In patients with shortening of the sciatic nerve secondary to a flexion contracture of the knee, hamstring lengthening may overstretch and damage the nerve. ${ }^{1-3}$ The amount of lengthening is usually based on clinical judgment. Some authors have suggested a pre-operative calculation to avoid damage to the sciatic nerve. ${ }^{2}$ Others have proposed elongating the hamstring up to an angle of flexion of the knee of $20^{\circ} .^{3} \mathrm{~A}$ decrease in nerve conduction can be measured as an indicator of possible nerve damage. ${ }^{4}$

The aim of our study was to determine the efficacy and feasibility of evoked electromyography (EMG) for monitoring the influence of hamstring lengthening on conduction in the sciatic nerve.

\section{Patients and Methods}

Five girls and five boys with spastic diplegia or total-body cerebral palsy underwent bilateral distal hamstring lengthening. The mean age at surgery was ten years (5 to 17). The indications for surgery were crouch gait or poor sitting posture due to short hamstrings.

The amount of shortening of the hamstrings was determined by measuring the angle of flexion of the knee. ${ }^{5}$ The mean angle before surgery was $70^{\circ}$ (60 to 80 ).

At surgery the children were placed prone. The tendons of the hamstrings were exposed through a transverse incision just above the popliteal crease. The gracilis tendon was divided and the semitendinosus tendon was Zlengthened. The semimembranosus and biceps muscles were elongated by an incision in the overlying aponeurosis. The patient was then placed supine, the hip and knee were flexed to $90^{\circ}$, and then the knee was slowly extended up to an angle of flexion of $30^{\circ}$, as recommended in previous studies (Fig. 1). ${ }^{1}$ The hip and knee were then extended. The knee was immobilised in plaster for three weeks in almost full extension, without applying any force. In this position the EMG amplitude returns to baseline. If any residual flexion contracture remained, no attempt was made to correct it by force.

The Explorer system (Biologic Corp, Mundelein, Illinois) was used for muscle stimulation and recording. To stimulate the nerve, two needle electrodes were placed near the peroneal nerve, and square impulses of amplitude from 0.18 to $1.2 \mathrm{~mA}$ were delivered for a duration of $100 \mu$ sec. Muscle responses were recorded using two needle electrodes inserted into the tibialis anterior muscle. The level of stimulation was fixed until a small twitch of the ankle was noted. The evoked EMG ampli- 


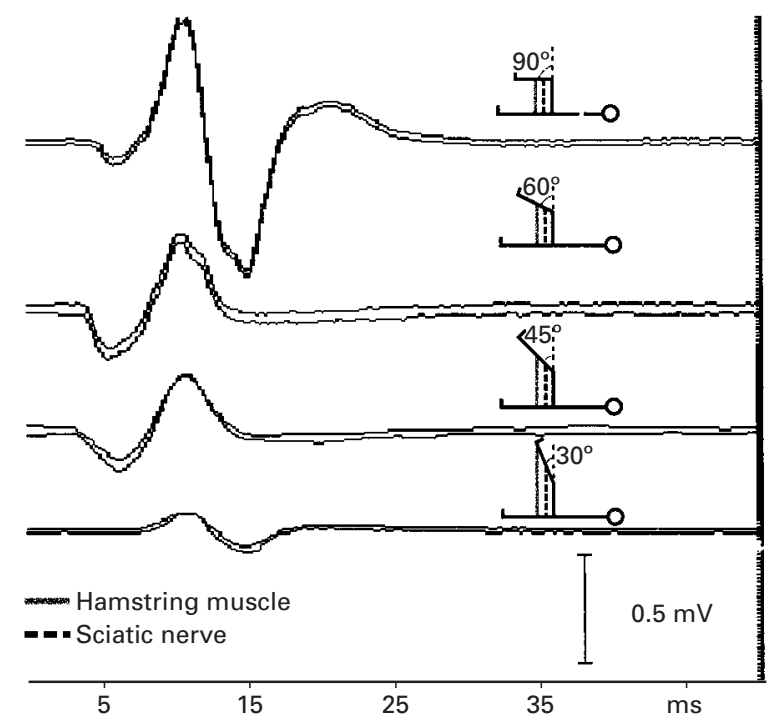

Fig. 1

The relationship between the gradual lengthening of the hamstring muscles with sciatic nerve stretch and its effect on the evoked EMG potential amplitude.

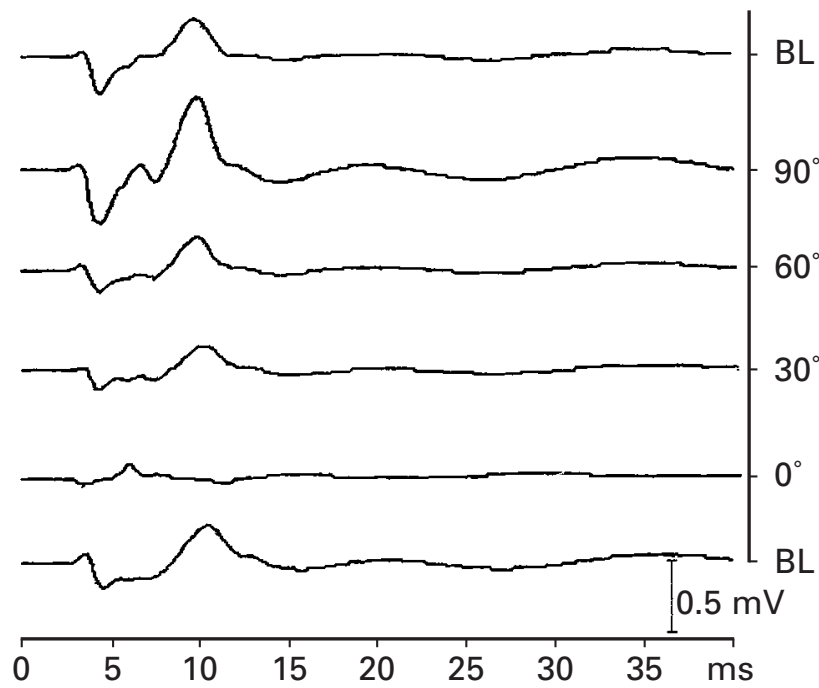

Fig. 2

Evoked EMG potential amplitudes during lengthening of the hamstring muscles at baseline (BL) and angles of flexion of the knee of $90^{\circ}, 60^{\circ}, 30^{\circ}$ and at the position of immobilisation in plaster $\left(0^{\circ}\right)$ for an eight-year-old girl (case 10).

(16 to 75 ) on the right. In most patients, there was a marked difference in the amount of decrease between the right and left sides (Table I). At an angle of $30^{\circ}$, the mean decrease was $89 \%$ (70 to 98 ) on the left side and 83\% (52 to 98 ) on the right.

In all patients, the evoked EMG amplitude returned to baseline on extension of the hip and knee to the normal position. None of the patients had signs of sciatic nerve injury at follow-up.

\section{Discussion}

Our study confirms previous reports that monitoring evoked EMG potentials enables serial real-time assessment of nerve conduction. A decrease in motor potential the amplitude of $35 \%$ (10 to 77 ) on the left side and $32 \%$

Table I. Clinical findings and changes in evoked EMG potential in ten children (20 legs) with cerebral palsy undergoing hamstring lengthening

\begin{tabular}{|c|c|c|c|c|c|c|c|c|c|}
\hline \multirow[b]{3}{*}{ Case } & \multirow[b]{3}{*}{ Gender } & \multirow{3}{*}{$\begin{array}{l}\text { Age } \\
\text { (yrs) }\end{array}$} & \multirow[b]{3}{*}{ Diagnosis } & \multirow{2}{*}{\multicolumn{2}{|c|}{$\begin{array}{l}\text { Popliteal angle } \\
\left.\text { before surgery ( }{ }^{\circ}\right)\end{array}$}} & \multicolumn{4}{|c|}{$\begin{array}{l}\text { Decrease in motor potential amplitude during } \\
\text { hamstring lengthening }(\%)\end{array}$} \\
\hline & & & & & & \multicolumn{2}{|c|}{ At popliteal angle of $60^{\circ}$} & \multicolumn{2}{|c|}{ At popliteal angle of $30^{\circ}$} \\
\hline & & & & Left & Right & Left & Right & Left & Right \\
\hline 1 & M & 9 & Diaplegia & 60 & 50 & 24 & 28 & 96 & 96 \\
\hline 2 & $\mathrm{M}$ & 17 & Diaplegia & 80 & 70 & 77 & 16 & 97 & 96 \\
\hline 3 & $\mathrm{~F}$ & 8 & Diaplegia & 70 & 70 & 52 & 75 & 87 & 91 \\
\hline 4 & M & 6 & Total body & 80 & 80 & 36 & 21 & 85 & 52 \\
\hline 5 & $\mathrm{~F}$ & 10 & Total body & 60 & 60 & 22 & 42 & 95 & 80 \\
\hline 6 & $\mathrm{~F}$ & 17 & Diaplegia & 80 & 80 & 18 & 45 & 98 & 89 \\
\hline 7 & $\mathrm{~F}$ & 8 & Total body & 80 & 70 & 23 & 27 & 98 & 98 \\
\hline 8 & M & 5 & Total body & 80 & 80 & 60 & 41 & 70 & 77 \\
\hline 9 & $\mathrm{M}$ & 16 & Diaplegia & 80 & 80 & 10 & 25 & 80 & 67 \\
\hline 10 & $\mathrm{~F}$ & 8 & Diaplegia & 80 & 80 & 27 & 32 & 81 & 88 \\
\hline
\end{tabular}


amplitude provides quantitative information about possible nerve injury. ${ }^{6}$ The cut-off decrease in motor potential amplitude, beyond which traction injury occurs in the sciatic nerve during slow hamstring elongation remains unknown. Our study shows that a gradual decrease of up to $98 \%$ for a few seconds does not cause nerve injury. In patients with short hamstrings and an angle of flexion of the knee of less than $80^{\circ}$, elongation of the hamstring up to an angle of $30^{\circ}$ is apparently safe. In patients with short hamstrings and an angle of $90^{\circ}$ or more, elongation of the hamstrings to within the normal range may be associated with sciatic nerve injury. ${ }^{2}$ In these patients we recommend that the hamstrings be elongated under EMG monitoring, up to a decrease of $98 \%$ in the motor potential amplitude.

Immobilisation of the leg for a long time can overstretch the sciatic nerve and result in nerve damage. ${ }^{2}$ One experimental study found that even minimal traction for more than two minutes can cause sciatic nerve damage. ${ }^{7}$ To avoid this complication, we recommend immobilising the leg in the position at which the evoked EMG amplitude returned to the pre-lengthening amplitude. If any residual flexion contracture remains after hamstring lengthening, no attempt should be made to correct it by force.

In conclusion, monitoring the evoked EMG potential amplitude during and after hamstring lengthening may avoid sciatic nerve traction injury.

The authors thank Gloria Ginzach and Charlotte Sachs of the Editorial Board, Rabin Medical Center, Beilinson Campus, for their assistance.

No benefits in any form have been received or will be received from a commercial party related directly or indirectly to the subject of this article.

\section{References}

1. Herring JA. Disorders of the brain. In: Tachdjian's pediatric orthopaedics. Third ed. Philadelphia: W.B. Saunders Company, 2002:1121-241.

2. Aspden RM, Porter RW. Nerve traction during correction of knee flexion deformity: a case report and calculation. J Bone Joint Surg [Br] 1994;76-B:471-3.

3. Bleck EE. Orthopaedic management in cerebral palsy. London: MAC Keith Press, 1987:282-391.

4. Nuwer MR, Daube J, Fischer C, Schramm J, Yingling CD. Neuromonitoring during surgery: report of an IFCN committee. Electroencephalog/ Clin Neurophysiol 1993;87:263-76

5. Katz K, Rosenthal A, Yosipovitch Z. Normal ranges of popliteal angle in children J Pediatr Orthop 1992;12:229-31.

6. Reeg SE. A review of comorbidities and spinal surgery. Clin Orthop 2001;384:101-9

7. Fowler SS, Leonetti JP, Bauich JC, et al. Duration of neuronal stretch correlates with functional loss. Otolarngol Head Neck Surg 2001;124:641-4. 